\title{
Influence of glycaemic normalisation by an artificial pancreas on phagocytic and bactericidal functions of granulocytes in insulin dependent diabetic patients
}

\author{
H GIN, E BROTTIER, J AUBERTIN \\ From the Clinique Médicale et des Maladies Infectieuses, Hôpital Pellegrin, 33076 Bordeaux Cedex, France
}

SUMMARY Ten insulin dependent diabetic patients were maintained in normoglycaemia for $36 \mathrm{~h}$ with an artificial pancreas. Circulating polymorphonuclear leucocytes were extracted and incubated with staphylococcus before and after treatment; phagocytic and bactericidal activities were studied. Granulocytes from diabetic patients showed a decreased ability to absorb staphylococcus and a reduced capacity for intracellular destruction of bacteria. These two functions were improved after $36 \mathrm{~h}$ of normoglycaemia but were not corrected.

The diabetic state decreases host resistance, ${ }^{\prime}$ and bacterial infection often occurs in diabetic patients. ${ }^{2}$ Usual sites of infection are the skin, lungs, urinary tract, and feet. Bacteraemia is more frequent; a local cause often explains the infection but other processes may be responsible. Most investigators agree that there is an increase in the severity of infections in poorly controlled diabetics; both cellular and immune defences may be altered. ${ }^{3}$

It is believed that hyperglycaemia and acidosis impair the functions of polymorphonuclear leucocytes and that improvement of these two disorders improves these functions. ${ }^{4}$ Not enough is known, however, about the relation of glucose concentrations to the phagocytic and bactericidal activity of granulocytes. We have therefore investigated phagocytic and bactericidal function before and after several hours of normoglycaemia achieved by means of an artificial pancreas.

\section{Patients and methods}

Ten insulin dependent (type I) diabetic patients (six men, four women) volunteered for the study. Their ages ranged from 19 to 55 years, and the duration of the diabetes ranged from two to 44 years. All patients had normal body weights. Mean blood glucose concentration before treatment with the artificial pancreas was $13.47 \pm 6.6 \mathrm{mmol} / \mathrm{l}$; there was no evidence of ketoacidosis. Mean alkaline reserve was 25-27 meq/l. No clinical or biological evidence of

Accepted for publication 12 April 1984 chronic or acute infection was found in any of the patients; none was taking immunosuppressive or other drugs.

Normal glucose concentrations were maintained for $36 \mathrm{~h}$ by means of an artificial pancreas (Biostator GCIIS, Miles Laboratories). Diet was not modified.

Measurement of bactericidal and phagocytic activity of neutrophilic granulocytes

A $20 \mathrm{ml}$ sample of heparinised blood was allowed to sediment on Dextran; the upper layer of leucocytes was removed and further concentrated by centrifuging for $10 \mathrm{~min}$ at $1500 \mathrm{rpm}$.

The sedimented cells were washed twice with Hank's solution and resuspended at a concentration of $1 \times 10^{7}$ cells $/ \mathrm{ml}$. An $18 \mathrm{~h}$ culture of Staphylococcus aureus was used in this investigation and a concentration of $10^{8} / \mathrm{ml}$ bacteria was obtained. Human serum was used as an opsonin. Half a millilitre of the granulocyte suspension, $0.1 \mathrm{ml}$ of the staphylococcal suspension, and $0.4 \mathrm{ml}$ of fresh human serum were mixed together and placed in a slowly rotating shaker apparatus to facilitate contact between granulocytes and bacteria. Samples were incubated at $37^{\circ} \mathrm{C}$ and aliquots of $0.05 \mathrm{ml}$ were added to $10 \mathrm{ml}$ of physiological saline; $0 \cdot 10 \mathrm{ml}$ of this suspension was incubated at $37^{\circ} \mathrm{C}$ on agar in Petri dishes. The number of colonies was a measure of the noningested bacteria, which correlated with the phagocytic activity. Other samples of $0.05 \mathrm{ml}$ were added to $10 \mathrm{ml}$ of distilled water; this caused osmotic breakage of the granulocytes and liberated live bacterial cells. Samples of the suspension $(0.10 \mathrm{ml})$ were incubated on agar. The number of colonies was 
a measure of bacteria which were ingested but not killed-that is, an index of bactericidal activity.

The study was thus conducted with the number of polymorphonuclear leucocytes remaining constant and without regard to the leucocytosis of the patients and the variation from one to another. Samples of leucocytes from normal subjects of the same age (two to each patient) were treated in a similar manner and acted as controls. The results of the investigation were evaluated by Student's $t$ test (assuming $p<0.05$ to be significant).

\section{Results}

The results are given as percentages of control values. The coefficient of variation of results obtained after 30,60 , and $90 \mathrm{~min}$ incubation was only $0 \cdot 05$. We therefore used a mean index. Before treatment with the artificial pancreas the phagocytosis index was less than 100 in all 10 patients; one of them was discounted for technical reasons. Substantial

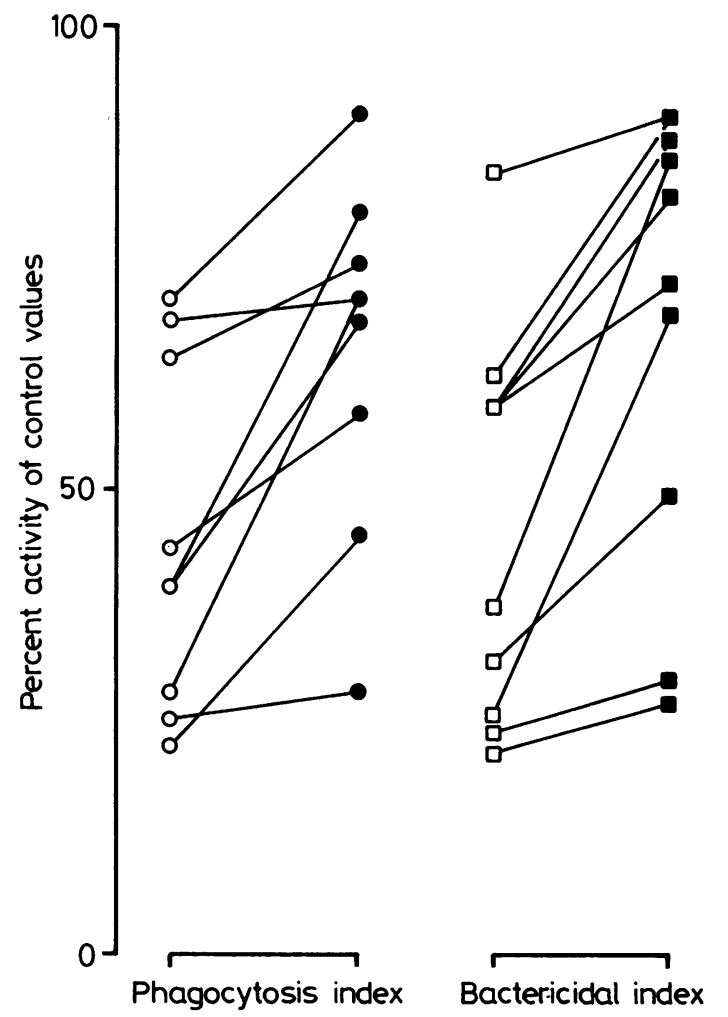

Evolution of phagocytosis and bactericidal index before $(\bigcirc \mathrm{Q})$ and after $\left(\mathrm{O}^{\circ}\right) 36 \mathrm{~h}$ of normoglycaemia achieved by means of an artificial pancreas in 10 insulin dependent diabetic patients free of ketoacidosis or infection. changes were found in some of them $(23 \%$ of the control value), but in others the change was less pronounced. After treatment with the artificial pancreas the phagocytosis index improved but never became normal. The mean index for all patients was $44.5 \% \pm 18.9$ (SEM) before treatment and $64.6 \%$ \pm 18 afterwards $(p<0 \cdot 05)$. The results are shown in the Figure.

The bactericidal index showed the same trend: it was always altered before treatment with the artificial pancreas and improved after treatment but it was never corrected. Mean bactericidal index before was $45 \cdot 1 \% \pm 22$ and $67 \cdot 2 \% \pm 25.6$ after. Results are shown graphically in the Figure $(p<0.05)$.

\section{Discussion}

The results of our investigations indicate that granulocytes of diabetic patients have decreased phagocytic and bactericidal activity. Both these functions are improved by normoglycaemia but are not completely corrected. These results are similar to those of Nolan et al, ${ }^{5}$ who reported that in uncontrolled diabetics with hyperglycaemia and acidosis the granulocytes had decreased phagocytic activity. After stabilising the diabetic state, the activity of the granulocytes improved but still remained below that of normal subjects. These authors did not study the influence of strict normoglycaemia. Niethammer et $a l^{6}$ and Kowalska $e t a l^{7}$ reported a normal ability of granulocytes of diabetics to absorb bacteria but a pronounced deficiency in bactericidal activity.

Phagocytosis depends on adherence between polymorphonuclear leucocytes and the microorganism; it also depends on the capacity of the leucocyte coat to become deformed and adapted, which is related to the energy produced by oxygen consumption. ${ }^{8}$

Intracellular bactericidal activity also depends on several systems: myeloperoxidase- $-\mathrm{H}_{2} \mathrm{O}_{2}$, superoxide anions, and molecular oxygen. ${ }^{9}$ The generation of these bactericidal oxygen systems depends on activation of the pentose phosphate pathway of glucose utilisation. ${ }^{10}$ Polymorphonuclear leucocyte activity is thus closely connected with carbohydrate metabolism. Granulocytes of a diabetic patient may have abnormalities in glucose metabolism and insulin may improve this carbohydrate metabolism.

Variations of function were found before normoglycaemia. These may depend on dysmetabolism but we did not correlate phagocytic and bactericidal function with glycaemia and glycosylated haemoglobin at the time of the venous puncture. Tan found no correlation between bactericidal function and glycaemia." Other factors such as acidosis could 
interfere, but acidotic patients were not included in the study.

After $36 \mathrm{~h}$ of normoglycaemia improvement of all functions took place due either to normoglycaemia or to insulin activity. No investigation of intracellular metabolism was performed. Esmann ${ }^{12}$ showed in vitro the part played by insulin. Bagdade ${ }^{4}$ found improvement in phagocytic function after eight or 15 days of strict control with three insulin injections daily. Similar results were achieved in our study after only $36 \mathrm{~h}$ of strict normoglycaemia. In those studies complete restoration of polymorphonuclear leucocyte function was never achieved. In our study improvement showed an individual variation, although the same procedure was applied to all patients. No correlation was found between improvement and initial abnormal metabolic state. This would suggest a variability in insulin action: either an insulin receptor defect or polymorphonuclear leucocyte insulin resistance would be expected. We did not study the adherence capacity of leucocytes, which Bagdade ${ }^{13}$ showed was improved by insulin.

The present investigation indicates that disturbances of carbohydrate metabolism or insulin deficiency diminish the phagocytic and bactericidal activity of granulocytes. Both functions quickly improve with strict control of glucose concentration. We therefore conclude that intensive insulin treatment may improve cellular host defences in diabetic patients.

\section{References}

' Robertson H, Polk H. The mechanism of infection in patients with diabetes mellitus: a review of leukocyte malfunction. Surgery 1974;75:123-8.
${ }^{2}$ Wheat LJ. Infection and diabetes mellitus. Diabetes Care 1980; 3:187-97.

${ }^{3}$ Rayfield E, Ault MJ, Keusch G, Brothers M, Nechemias C, Smith $\mathrm{H}$. Infection and diabetes: the case for glucose control. Am J Med 1982;72:439-50.

${ }^{4}$ Bagdade JD, Root RK, Bulger RJ. Impaired leukocyte function in patients with poorly controlled diabetes. Diabetes 1974; 23:5-9.

${ }^{5}$ Nolan CM, Beaty HN, Bagdade JD. Host defence in diabetes mellitus: granulocyte antibacterial function. Clin Res 1975;23:29 A.

${ }^{6}$ Niethammer D, Heinze E, Teller W, Kleihaver E, Wildfever A, Haferkamp O. Impairment of granulocyte function in juvenile diabetes. Klin Wochenschr 1975;53:1057-60.

' Dziatkowiak H, Kowalska M, Denys A. Phagocytic and bactericidal activity of granulocytes in diabetic children. Diabetes 1982;31:1041-3.

${ }^{8}$ Walters MI, Lessler MA, Stevenson TD. Oxidative metabolism of leukocytes from non diabetic and diabetic patients. $J \mathbf{L a b}$ Clin Med 1971;78:158-66.

${ }^{4}$ Root R, Cohen M. The microbicidal mechanism of human neutrophils and eosinophils. Review of Infectious Diseases 1981;3:565-97.

${ }^{10}$ Oren R, Farnham AE, Satto K, Milofsky E, Karnovsky ML. Metabolic patterns in three types of phagocytizing cells. J Cell Biol 1963;17:487-501.

"Tan J, Anderson JC, Watanaknakorn C, Phair JP. Neutrophil dysfunction in diabetes mellitus. J Lab Clin Med 1975;85:23-6.

${ }^{12}$ Esmann V. Effect of insulin on human leucocytes. Diabetes 1963; 12:545-9.

${ }^{13}$ Bagdade JD, Walters E. Impaired granulocyte adherence in mildly diabetic patient: effect of tolazamide treatment. Diabetes 1980;29:309-11.

Requests for reprints to: Dr $\mathbf{H}$ Gin, Chef de CliniqueAssistant, Clinique Médicale, Tripode Höpital Pellegrin, 4e étage, Place Amelie Raba Léon, 33000 Bordeaux, France. 